\title{
Pathological and therapeutic roles of bioactive peptide trefoil factor 3 in diverse diseases: recent progress and perspective
}

\author{
Yiqi Yang (iD ${ }^{1,2}$, Ziyang Lin $\mathbb{D}^{1,2}$, Quanyou $\operatorname{Lin}^{1}$, Weijian Bei $\mathbb{D}^{1}$ and Jiao Guo (D) ${ }^{\text {网 }}$
}

(c) The Author(s) 2022

Trefoil factor 3 (TFF3) is the last small-molecule peptide found in the trefoil factor family, which is mainly secreted by intestinal goblet cells and exerts mucosal repair effect in the gastrointestinal tract. Emerging evidence indicated that the TFF3 expression profile and biological effects changed significantly in pathological states such as cancer, colitis, gastric ulcer, diabetes mellitus, non-alcoholic fatty liver disease, and nervous system disease. More importantly, mucosal protection would no longer be the only effect of TFF3, it gradually exhibits carcinogenic activity and potential regulatory effect of nervous and endocrine systems, but the inner mechanisms remain unclear. Understanding the molecular function of TFF3 in specific diseases might provide a new insight for the clinical development of novel therapeutic strategies. This review provides an up-to-date overview of the pathological effects of TFF3 in different disease and discusses the binding proteins, signaling pathways, and clinical application.

Cell Death and Disease (2022)13:62; https://doi.org/10.1038/s41419-022-04504-6

\section{FACTS}

- TFF3 is the driving factor of cancer, which is involved in the proliferation, invasion, resistance to apoptosis, and angiogenesis of cancer cells.

- TFF3 is a promising novel neuropeptide that regulates diverse brain functions.

- Hepatic TFF3 may serve as therapeutic targets for glycolipid metabolic diseases.

- TFF3 is widely distributed in human body, and is also present as a mixed ligand, regulating multiple signal pathways.

\section{OPEN QUESTIONS}

- Which upstream links contribute to dysregulation of TFF3 expression during cancer progression?

- What factors determine the carcinogenic effect of TFF3, and how is the balance between mucosal protection and carcinogenesis achieved?

- How does TFF3 participate in the innate immune protection of the host and can it regulate the proliferation and differentiation of immune cells?

- What factors hinder the clinical efficacy of TFF3 in colitis?

\section{INTRODUCTION}

Trefoil factor peptides (TFFs) are small molecular peptides secreted by goblet cells and epithelial cells of various tissues in mammals. The trefoil factor family comprises three members, namely gastric peptide (TFF1 or pS2), spasmolytic polypeptide (TFF2 or SP), and intestinal trefoil factor (TFF3 or ITF). TFF3 contains 59 amino acids and a seventh free cysteine residue at position 57 , which is crucial for dimer formation [1]. Although dimerization is not necessary for TFF function, the dimer is the more potent form than the monomer. For instance, TFF1 dimers promoted cell migration eight times more efficiently than the monomers [2]. Intracolonic injection of TFF3 dimers (but not monomers) ameliorates experimental colitis in rats [3]. The antiapoptotic effect of TFF3 depends on the intact dimerized peptide [4].

Recent studies have reported that TFF3 is present in not only the intestinal tract but also the brain [5], liver [6], kidney [7], pancreas [8], breast [9], lung [10], conjunctiva [11], spleen, and lymph nodes [12] (Table 1). It participates in the pathological process of various diseases such as type 2 diabetes mellitus (T2DM), non-alcoholic fatty liver disease (NAFLD), neurodegeneration, gastric ulcer, colitis, and cancer. However, the biological functions and specific mechanisms of TFF3 expressed in these tissues remain unclear. Despite consistent reports regarding the highly promising mucosal healing capacity of TFF3 [13], till date, drugs developed using TFF3 have not made significant progress in clinical practice. For a long time, several attempts to isolate TFF-binding proteins with typical receptor characteristics have failed [14], leading to considerable gaps in our understanding of TFF3 at the molecular level. These gaps hinder its application and development in clinical medicine.

\footnotetext{
${ }^{1}$ Key Laboratory of Glucolipid Metabolic Diseases of the Ministry of Education, Guangdong Metabolic Diseases Research Center of Integrated Chinese and Western Medicine, Guangdong Pharmaceutical University, Science and Technology Building, 280 Waihuan East Road, Guangzhou Higher Education Mega, Guangzhou, China. ${ }^{2}$ These authors

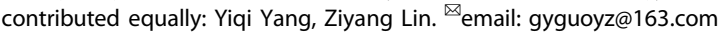

Edited by Professor Gerry Melino
}

Received: 27 July 2021 Revised: 23 December 2021 Accepted: 30 December 2021

Published online: 17 January 2022 
Table. 1. TFF3 distribution in samples from healthy humans.

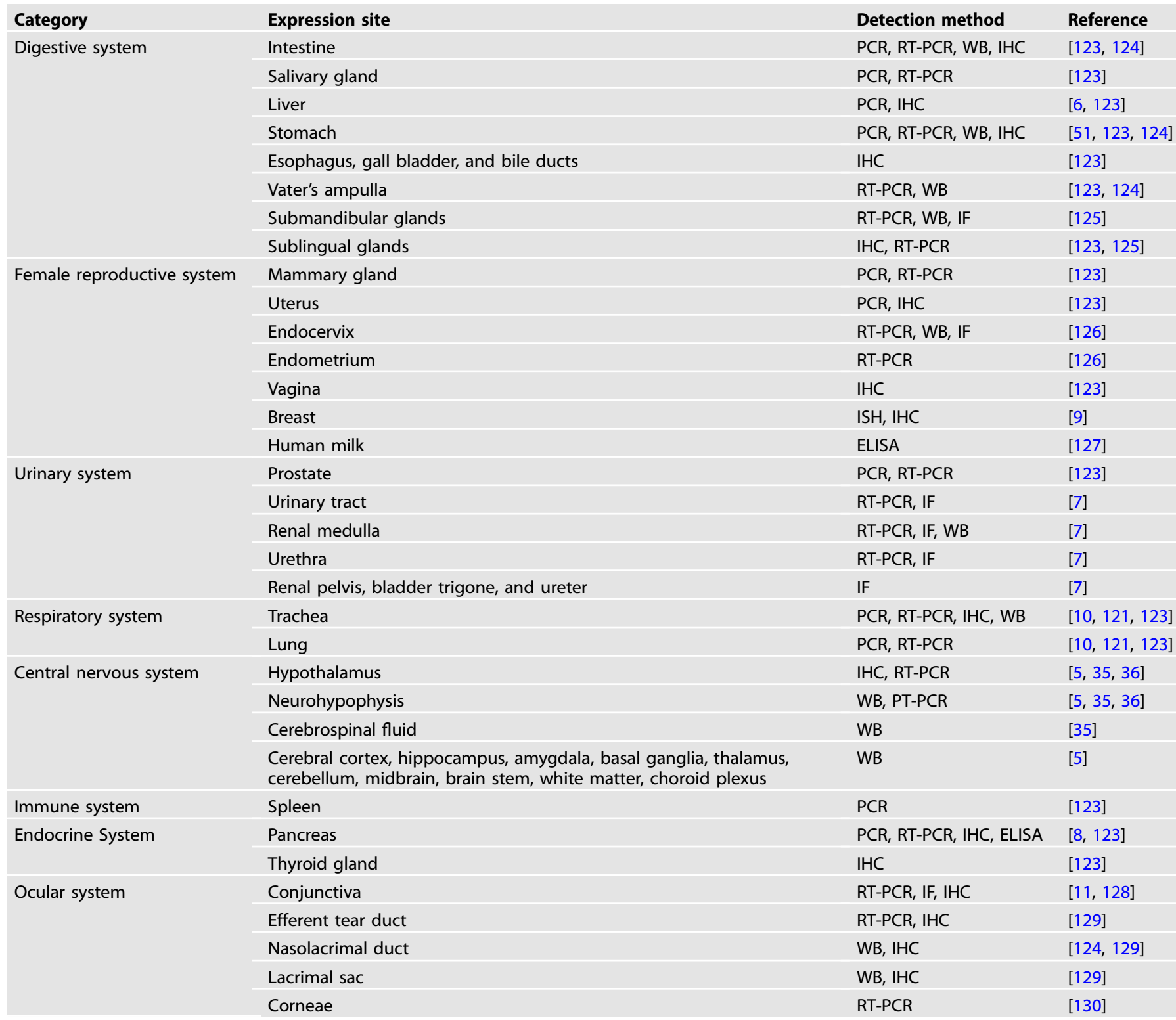

WB western blot, IHC immunohistochemistry, IF immunofluorescence, ISH in situ hybridization, RT-PCR reverse transcription-polymerase chain reaction, ELISA, enzyme linked immunosorbent assay.

In this review, we present and discuss the biological effects, binding proteins, proposed mechanisms, and clinical applications of TFF3 in currently researched diseases.

\section{DISEASE PHENOTYPES IN TFF3 DEFICIENCY MICE}

Colitis is the first and most concerning disease to be studied using $\mathrm{TFF}^{-1-}$ mice. Since TFF3 plays an important role in the protection of the intestinal barrier, its deficiency not only renders the body particularly sensitive to glucan sodium sulfate, chemotherapy, and radiation-induced mucosal damage, but also induces markedly poor epithelial regeneration, leading to extensive death of mice from colitis $[15,16]$. Similarly, epithelial regeneration defects were observed in corneal injury models of $\mathrm{TFF}^{-/-}$mice, and the completed wound healing extended to $462 \mathrm{~h}$ after corneal injury, which almost 5 times of wild-type mice $(98 \mathrm{~h})$; while exogenous TFF3 administration can accelerate corneal wound healing in a dose-dependent manner in vivo [17]. Interestingly, disruption of the TFF3 gene does not affect the normal morphological development of the cornea [17]. It has been suggested that TFF3 is required for corneal wound healing but not for physiological maintenance of the corneal epithelium. This is of great significance for the treatment of infectious keratitis induced by delayed epithelial healing after excimer laser surgery.

Metabolic diseases and brain diseases are new directions in $\mathrm{TFF}^{-1-}$ mice research in recent years. Compared with wild-type mice, TFF $3^{-1-}$ mice exhibited not only a lower body weight but also significant dysregulation of 21 miRNAs [18]. Most of these miRNAs were related to the metabolic pathway "glycolysis/ gluconeogenesis" [18]. Further research indicated that adenovirus-induced TFF3 knockdown leads to a pronounced fatty-liver phenotype [19]. Conversely, intraperitoneal injection of recombinant TFF3 protein or tail-vein injection of adenovirusmediated TFF3 overexpression ameliorated several indicators 
associated with NAFLD in diabetic and obese mice. Furthermore, TFF3 deficiency may also affect vascular function and stroke outcome. In a model of brain injury induced by transient occlusion of the middle cerebral artery, high-salt diet resulted in significant reduction in endothelium-dependent vasodilation of carotid arteries in $\mathrm{TFF}^{-1-}$ mice, and their cerebral infarction area was larger than that in wild-type mice [20]. Furthermore, compared with wild-type mice, experimental cerebral ischemia/reperfusion $\mathrm{TFF}^{-1-}$ mice exhibited higher caspase 3 activity and cell death, larger cerebral infarction area, and more severe forelimb motor defects [21]. Intravenous administration of recombinant TFF3 can reverse brain damage and TFF3-deficiency-induced changes in forelimb motor function [21]. The above results suggested that $\mathrm{TFF}^{-/-}$mice could be used as a potential new model for glycolipid metabolism and cerebrovascular function research.

In summary, phenotypic changes caused by TFF3 deficiency include intestinal epithelial and corneal regeneration defects, accelerated presbyopia and hearing impairment, weight loss, abnormal lipid metabolism, and impaired vascular function (Table 2). TFF ${ }^{-1-}$ mice may be a useful model to study the pathogenic process of inflammatory enteritis, stroke, NAFLD and keratitis, and it is of great significance for disease treatment and drug development targeting TFF3.

\section{PATHOLOGICAL EFFECTS OF TFF3 IN DISEASE TFF3 in T2DM}

T2DM is a chronic disease that results from insulin resistance. It can lead to various complications, such as chronic kidney disease (CKD). Clinical studies have shown that the level of serum TFF3 increased significantly in patients with T2DM and its complications [22-25]. This change was more obvious in patients with CKD. The serum TFF3 can be used to predict the decline of glomerular filtration rate and occurrence of CKD. It is a valuable diagnostic marker for early CKD in dysglycemic populations [22]. Interestingly, glucose and insulin can dose-dependently enhance the secretion of TFF3 by intestinal epithelial cells [26]. Additionally, short-chain fatty acids can dose-dependently inhibit the synthesis and release of TFF3, which may be mediated by transcription [27]. Therefore, the increase in blood glucose and insulin and decrease in short-chain fatty acids in patients with T2DM may potentially lead to the elevation of serum TFF3. Adenoviral-vector-mediated TFF3 overexpression or daily injection of recombinant TFF3 protein in vivo can improve glucose tolerance and insulin sensitivity and reduce blood glucose levels in diabetic or obese mice $[28,29]$, possibly through a reduction in hepatic glucose output by inhibiting gluconeogenic genes expression via activation of the AKT signaling pathway $[28,29]$ (Fig. 1A). These studies suggested that TFF3 is involved in hepatic glucose homeostasis, which provided a promising new lead for developing therapies against the metabolic disorders associated with T2DM.

\section{TFF3 in NAFLD}

NAFLD is the hepatic manifestation of metabolic syndrome, with a prevalence as high as $29.2 \%$ in China [30]. It is a metabolic disease involving fatty degeneration and lipid accumulation in liver cells induced by insulin resistance. Microarray analysis showed that TFF3 was one of the most affected liver genes in rodent models of early fatty liver and diabetes $[28,31]$. TFF3 gene expression is significantly downregulated in the livers of $\mathrm{db} / \mathrm{db}$, ob/ob, and high-fat diet-induced obese mice and changes most dramatically (600-fold reduction) in the early diabetic stage of a multigene diabetic model called Tally Ho mice [32]. Thus, TFF3 is increasingly recognized as a novel participant in NAFLD.

TFF3 was detected in both cell culture medium and cell extracts after adenovirus-TFF3-infected primary mouse hepatocytes indicating that it is efficiently secreted from primary hepatocytes [28].
In contrast, TFF3 deficiency impairs fatty-acid distribution and accumulation in mouse liver, showing reduced expression of metabolism-related genes and increased number of small lipid vesicles [33, 34], raising the possibility that TFF3 affects hepatic lipid-droplet formation. Conversely, intraperitoneal injection of recombinant TFF3 protein or tail-vein injection of adenovirusmediated TFF3 overexpression ameliorated several indicators associated with NAFLD in diabetic ( $\mathrm{db} / \mathrm{db}$ ), obese (ob/ob), and diet-induced obese mice or rats, possibly by mediating hepatic fatty-acid oxidation via increasing peroxisome proliferatoractivated receptor-a levels [19] (Fig. 1A). Thus, hepatic TFF3 may serve as a potential therapeutic target for NAFLD.

\section{TFF3 in nervous system disease}

Neuropeptides, the most common signaling molecules in nervous system disease, regulate a wide range of brain functions. Recent studies have shown that TFF3 protein is a novel neuropeptide expressed in various brain regions in humans, including the hypothalamus, pituitary gland, hippocampus, temporal cortex, and cerebellum $[5,35,36]$. Clinical findings have shown that TFF3 is the strongest predictor of neurodegeneration across the spectrum of cerebral amyloidosis, with significant reductions in TFF3 levels observed in patients with vascular parkinsonism dementia, Parkinson's disease dementia, and Alzheimer's disease $[37,38]$. Similarly, TFF3 ${ }^{-1-}$ mice has been shown to induce hearing impairment, accelerated presbycusis, and worsened stroke outcomes [20,39,40]. These observations imply that TFF3 plays non-negligible roles in both physiological and pathological processes.

Indirect evidence proved that after systemic administration, TFF3 can cross the blood-brain barrier, enter the brain after 30 min of administration [41], and produce sustained long-term memory, anxiolytic, and antidepressant effects [41-44]. Injection of specific inhibitors of phosphoinositide 3-kinase (PI3K), extracellular signalregulated kinase (ERK), or brain-derived neurotrophic factor (BDNF) blocked the antidepressant-like effects produced by TFF3 in rats $[41,44]$. These results suggest that the antidepressant-like effect of TFF3 may be mediated by the PI3K/AKT signaling pathway in the basolateral amygdala, as well as the BDNF/ERK/cyclic-adenosinemonophosphate-response-element-binding protein signaling pathway in the hippocampal CA (Fig. 1B). In a passive-avoidance test, injection of different doses of TFF3 into the amygdala of rats appeared to affect anxiety bidirectionally in a dose-dependent manner. A low dose was anxiolytic, whereas a high dose produced an anxiogenic effect [42]. In addition to administering TFF3, inducing nerve cells to secrete TFF3 may act as a potential therapeutic approach. Astrocytes are a source of TFF3 in the central nervous system of rats; they can significantly reduce the secretion of TFF3 under stimulation by lipopolysaccharide [45]. In contrast, microglia cultured in the presence of TFF3 showed decreased secretion of pro-inflammatory cytokines such as inducible nitric oxide synthase, interleukin (IL)-6, IL-1 $\beta$, and tumor necrosis factor- $\alpha$ (TNF-a) after lipopolysaccharide stimulation. Furthermore, TFF3 played a regulatory role in drug abuse. The underlying mechanisms involve the activation of mammalian target of rapamycin (mTOR) signaling in the nucleus accumbens shell [46] and downregulation of the hypothalamic-pituitary-adrenal-axis activity through glucocorticoid receptors [47]. In summary, TFF3 can improve memory; regulate drug addiction; and produce anxiolytic, antidepressant, and anti-neuroinflammatory effects (Table 3).

\section{TFF3 in gastric ulcer}

Gastric ulcer is the most common type of peptic ulcer, with an estimated lifetime prevalence of $5-10 \%$ in the general population [48]. Excessive gastric-acid secretion and weakened gastric mucosal protection are the main factors that cause peptic ulcer. Many factors contribute to the protection of mucosal surfaces throughout the gastrointestinal tract. For example, when peptic 


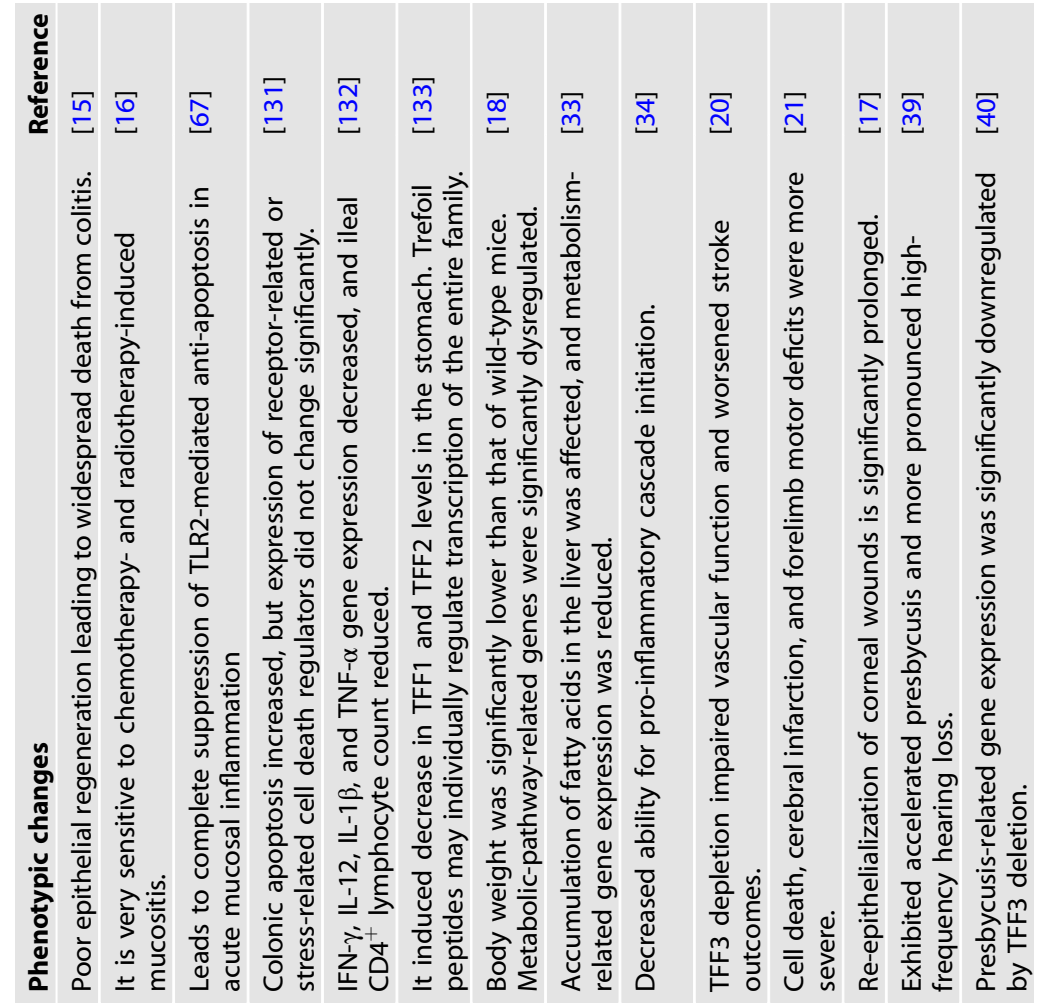

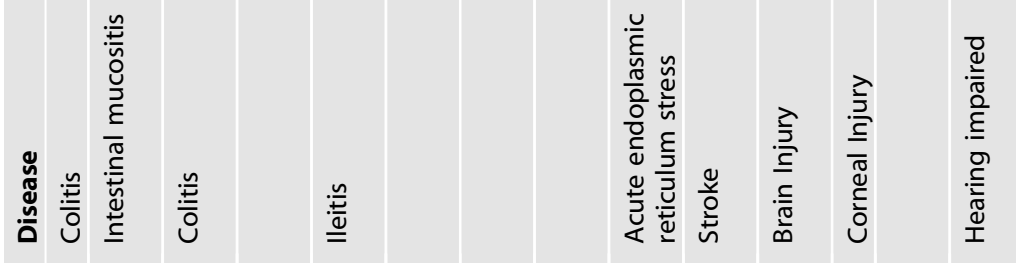

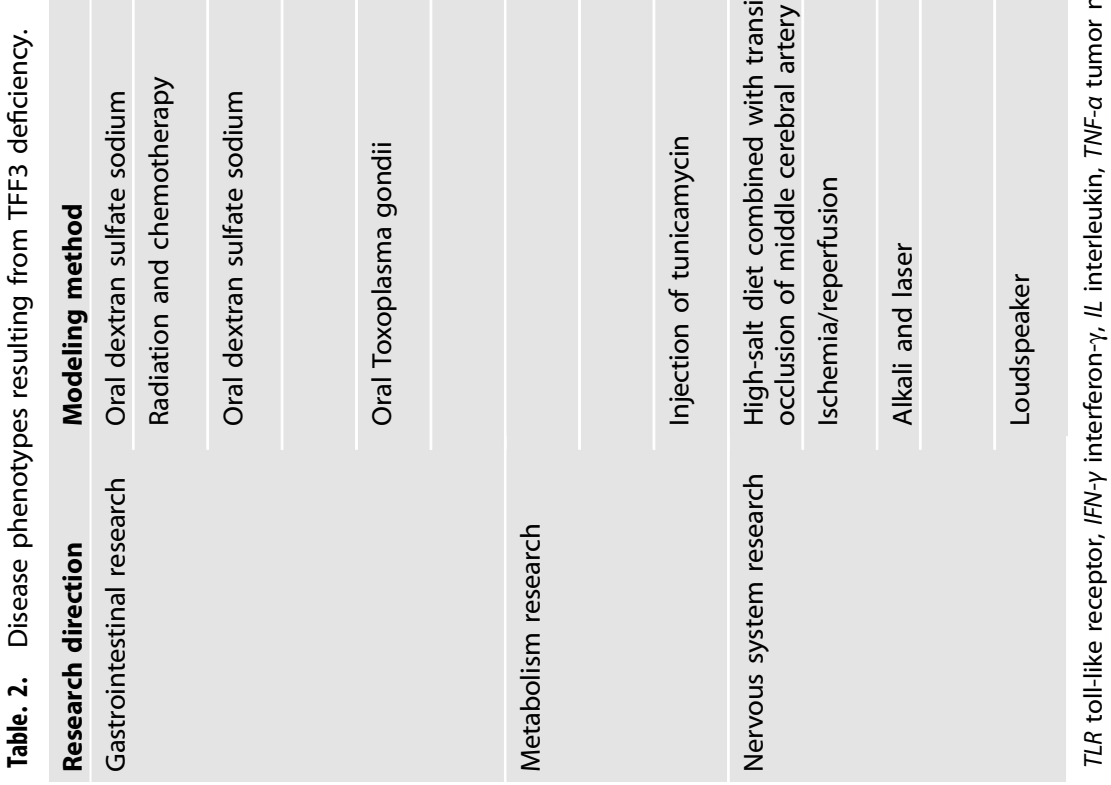




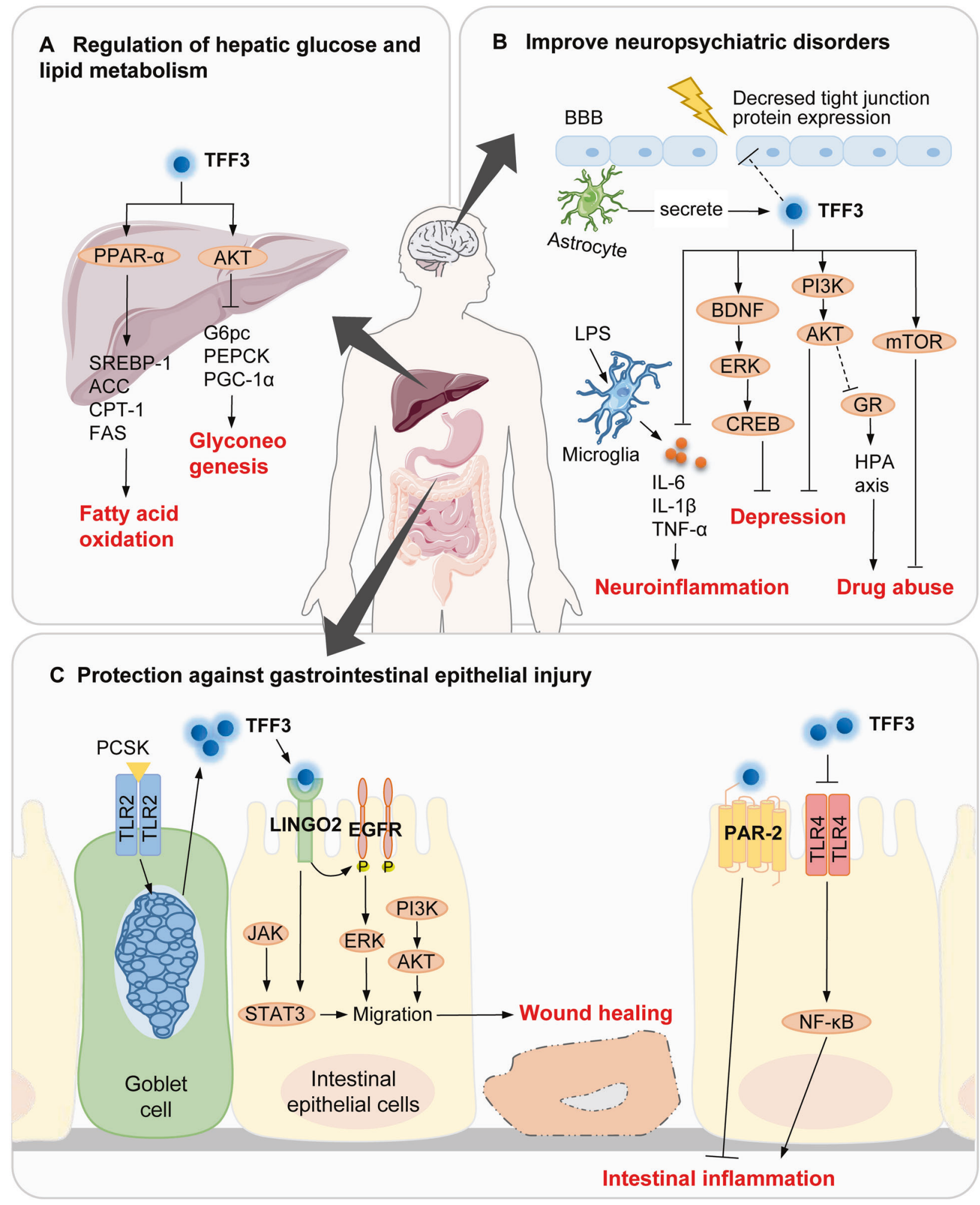

ulcer occurs, ulcer-associated cell lineage promotes ulcer restitution by secreting TFF peptides, epidermal growth factor, and transforming growth factor-a [49]. Detection of TFF3 expression is difficult in normal gastric mucosal tissues, as TFF3 tends to be expressed in the marginal area of the stomach, i.e., the cardia and antrum [50, 51]. However, TFF3 expression is enhanced in the gastric mucosa and periulcer tissues of patients and rats with gastric ulcer. A significant increase in TFF3 mRNA was detectable as early as day 2 after ulcer induction [52]; the level steadily increased at the ulcer margin after day 4 By 40 days, the TFF3 levels were elevated several hundred folds [53].

Animal studies have shown that TFF3 administration reduced gastric mucosal damage caused by alcohol, pylorus ligation, nonsteroidal anti-inflammatory drugs, stress, and lipopolysaccharide (Table 4). Its effects include maintaining the gastric $\mathrm{pH}$, stimulation of mucosal healing without proliferation [54], and 
Fig. 1 Mechanisms of TFF3 in metabolic diseases, nervous system diseases, and gastrointestinal disorders. A In the liver, TFF3 regulates fatty-acid oxidation and gluconeogenesis-related proteins through the PPAR- $\alpha$ and AKT pathways, respectively, to ameliorate T2DM and NAFLD. B TFF3 can regulate occludin, claudin-1, and ZO-1. These major tight-junction proteins of the blood-brain barrier may be downregulated because of age, inflammation, and stress, triggering nervous-system diseases. TFF3 additionally exerts anti-neuroinflammatory, antidepressant, and anti-drug-addictive properties; the underlying mechanisms are related to the BNDF/ERK/CREB, PI3K/AKT, mTOR, and GR signaling pathways, as well as the suppression of inflammatory secretion by microglia. Systemic TFF3 administration or induction of TFF3 secretion from astrocytes could be potential treatments. C TLR2 ligands, such as synthetic Pam3CysSK4, stimulates TFF3 secretion from goblet cells, and TFF3 can interact with LINGO2 to enhance EGFR signaling and subsequently promote epithelial cell migration to achieve wound healing. Furthermore, TFF3 suppressed intestinal inflammation via PAR-2 and TLR4/NF- $\mathrm{kB}$ signaling. Established functions are denoted by solid arrows, whereas unidentified pathways are indicated by question marks. PPAR- $\alpha$, peroxisome proliferatoractivated receptor alpha; SREBP-1, sterol regulatory element binding protein 1; ACC, acetyl-CoA carboxylase; CPT-1, carnitine palmitoyltransferase 1; FAS, fatty acid synthase; G6PC, glucose- 6 phosphatase catalytic subunit; PEPCK, phosphoenolpyruvate carboxykinase; PGC-1 $\alpha$, peroxisome proliferator-activated receptor- $\gamma$ coactivator- $1 \alpha$; BBB, blood-brain barrier; LPS, lipopolysaccharide; IL, Interleukins, TNF- $\alpha$, tumor necrosis factor; BDNF, brain-derived neurotrophic factor; ERK, extracellular signal-related kinase; CREB, cyclic adenosine monophosphate response element binding protein; PI3K, phosphatidylinositol 3-kinase; GR, glucocorticoid receptor; HPA axis, hypothalamic pituitary adrenal axis; mTOR, mammalian target of rapamycin; PCSK, Pam3CysSK4; TLR, toll-like receptors; LINGO2, leucine-rich repeat receptor and nogo interacting protein 2; EGFR, epidermal growth factor receptor; STAT, signal transducer and activator of transcription, PAR, proteaseactivated receptor; NF-кB: nuclear factor $\kappa \mathrm{B}$.

local effects [55]. The protective effect is even more pronounced when mucus glycoproteins or epidermal growth factor are administered concomitantly [54, 56]. Unlike that of many gastroprotective agents, the gastroprotective effect of TFF3 is independent of prostaglandin (PG). This effect appears to be achieved at the mucosal luminal surface [55]. There are few studies on the gastroprotective effect of TFF3. Currently, it is only known that it may be achieved by activating the PI3K/AKT signaling pathway [57].

\section{TFF3 in colitis}

The intestinal epithelium is the main barrier that protects us from bacteria and immunogenic or toxic luminal contents. Intestinal barrier dysfunction favors aberrant antigen uptake and immunecell infiltration, triggering uncontrolled inflammation that progresses to colitis. Intestinal goblet cells can secrete TFF3 and mucin2 (MUC2), and they are bound in soluble portions of the intestinal mucus by covalent interactions to form heteropolymers, which in turn constitute the first line of defense at the intestinal barrier [58]. TFF3 ${ }^{-1-}$ mice showed in increased colonic mucosal permeability and sensitivity to dextran sulfate sodium, as well as poor epithelial regeneration [15, 59]. Different administration methods for TFF3 dimer significantly ameliorated the severity of colitis induced by dextran sodium sulfate, radiochemotherapy, hypoxia, and trinitrobenzene sulfonic acid (Table 4). Notably, a detailed comparative study demonstrated that intraluminal administration was more effective than systemic administration [3]. Subcutaneous injections and especially administration of TFF3 monomers aggravate colitis induced by mitomycin $\mathrm{C}$ or dextran sulfate sodium salt [3]. Moreover, the monomeric and dimeric forms of TFF3 are functionally different. The pro-proliferative and anti-apoptotic functions of TFF3 have been reported to require homodimerization $[3,4,60]$, whereas exerting a pro-migratory effect does not require an intact trefoil domain or dimerization [4].

TFF3 rapid responds to injury, and it can reduce intestinal epithelial permeability by regulating tight junctions [61-63], an effect that can be attenuated by inhibition of the PI3K/AKT signaling pathway [64]. In addition, the process of restitution requires TFF3 to act as a motogen, by promoting epithelial cell elongation and migration to cover the exfoliated surface. Studies have shown that TFF3 treatment enhances the collective migration of IEC-18 cells and forms continuous sheets of migrating cells to ensure precise coverage of the repopulated area [65]. The number of migrating cells after treatment with ERK and Janus kinase (JAK) inhibitors was lower than that after treatment with either inhibitor alone [66]. It is suggested that TFF3 may promote intestinal mucosal reconstitution through crosstalk between ERK and JAK/signal transducer and activator of transcription (STAT3) pathways (as shown in Fig. 1C).

Inhibition of inflammatory response is an important mechanism through which TFF3 ameliorates colitis. Because of the destruction of intestinal barrier, activated leukocytes are recruited to the lamina propria, and they secrete a large number of cytokines, which is the key event causing intestinal mucositis. TFF3 has been shown to be regulated by cytokines and toll-like receptor (TLR) signaling. TLR2 ligands can stimulate intestinal goblet cells to selectively synthesize a large amount of TFF3. Similarly, TLR2-deficient mice showed innate immune deficiency of goblet-cell-derived TFF3 [67]. TFF3 and TLR2 are functionally linked, and overexpression of both blocked IL1 $\beta$-induced upregulation of proinflammatory cytokines via the PI3K/AKT pathway [64]. Nuclear factor $\mathrm{KB}(\mathrm{NF}-\mathrm{KB})$ is considered the main regulator of intestinal inflammatory response. TFF3 inhibits NF$K B$ activity via the TLR4 and ERK/twist signaling pathways, thereby attenuating the inflammatory reaction of IEC-18 cells and mouse intestines [68-72]. Moreover, the addition of TFF3 isolated from human milk to HT29 cells inhibited LPS-induced IL6 and IL- 8 secretion, a process dependent on protease-activated receptor 2 (PAR-2) [73, 74]. Interestingly, leucine-rich repeat receptor and nogo-interacting protein 2 (LINGO2) was detected in immune cells, including $\mathrm{CD} 4{ }^{+} \mathrm{T}$ cells, myeloid cells, and $\mathrm{B}$ cells [75]. LINGO2 was confirmed to capture TFF3 at $40 \mathrm{~nm}$ of the epithelial cell membrane. The TFF3-LINGO2 interaction led to enhanced epidermal growth factor receptor (EGFR) activation, which promoted wound healing and immunity [75]. Therefore, it is highly worth investigating whether TFF3 interacts with the LINGO2 of immune cells to regulate intestinal inflammation.

\section{TFF3 in cancer}

The GLOBOCAN reports almost 10 million deaths from cancer in 2020, rendering cancer a leading cause of death worldwide [76]. Emerging evidence suggests that TFF3 is significantly upregulated in cancers such as gastric cancer, colorectal cancer, lung cancer, thyroid cancer, and breast cancer and that it plays a key role in tumor progression [77]. The occurrence and development of cancer mainly involves the proliferation, metastasis, angiogenesis, and resistance to apoptosis of tumor cells. TFF3 is involved in these four important carcinogenic processes through mitogenactivated protein kinase (MAPK)/ERK, PI3K/AKT, STAT3, and hypoxia-inducible factor (HIF)-1a signaling pathways (Fig. 2 and Supplementary Tables 1, 2 and 3). For example, the use of siRNA to silence TFF3 in cancer cells inhibited of MAPK/ERK signaling pathway [78, 79], leading to a significant decrease in cell survival, whereas exogenous administration of TFF3 significantly activated the ERK pathway and promoted cancer-cell invasion [4, 80]. Hypoxia is an early signal for induction of the tumor angiogenesis 
switch. It time-dependently induced TFF3 expression in colonic, gastric, and renal tubular epithelial cells [81-83]. The promoter region of TFF3 contains binding sites for HIF-1a; blocking HIF-1a expression substantially decreased TFF3 mRNA expression over 4 and $24 \mathrm{~h}$ of hypoxia [81]. TFF3 overexpression time-dependently upregulated hypoxia-induced vascular endothelial growth factor and HIF-1a mRNA expression [84]. These results suggested that TFF3 may be mutually induced with HIF-1a, promoting angiogenesis. Furthermore, the promoter region of TFF3 contains binding sites for STAT3, which enables self-induction of TFF3 [85]. STAT3 inhibition has been consistently shown to hinder the proliferation, invasion, and survival of TFF3-induced cancer cells [66, 86-89].

A novel specific small-molecule TFF3 inhibitor, AMPC, disrupted dimerization with TFF3 by exploiting the cysteine- 57 residue essential for TFF3 homodimerization. Since monomeric TFF3 is characterized by faster degradation than dimeric TFF3, inhibiting its homodimerization could promote TFF3 depletion [90]. Studies showed that AMPC dose-dependently decreased TFF3 expression in estrogen-receptor-positive mammary carcinoma cells, lung adenocarcinoma cells, and mesenchymal colorectal carcinoma cells, which induced tumor-volume reduction in mice [78, 91, 92]. AMPC in combination with anticancer agents (5-fluorouracil or doxorubicin) produced synergistic tumor-suppressive effects. In the future, TFF3 may be used as a molecular target of functional antagonism in combination with other chemotherapeutic drugs to slow down cancer progression.

\section{FUNCTIONAL PROTEINS AND RECEPTORS OF TFF3 MUC2, FCGBP, and DMBT1}

Although MUC2, IgG Fc-binding protein (FCGBP), and Deleted in malignant brain tumor 1 (DMBT1) are TFF3-binding partners that were identified early on, none of them appear to possess the typical receptor characteristics, and there is no evidence that their binding can transmit signals to cells. MUC is a major component of the mucus layer covering the intestinal surface, which sequesters gut microbes from contact with host epithelial and immune cells and plays an important role in maintaining mucosal homeostasis. MUC are closely related to TFFs because they are usually secreted by goblet cells together. Each member of the TFF family is co-localized with the designated MUC type, for example, TFF1 with MUC5AC, TFF2 with MUC6, and TFF3 with MUC2 $[49,93,94]$. Studies in intestinal epithelial cell restitution models have found that although TFFs alone can increase the migration rate of cells to the wound site by 3-6 times, the combined use of TFFs and MUC can considerably increase the rate up to 15 times [56].

FCGBP, the Fc portion of the lgG-binding site in the intestinal epithelium, is an important component of the mucosal immune defense [95]. FCGBP in the intestine and saliva is the disulfide linkage partner protein of TFF3 $[96,97]$. TFF3 can be released from purified TFF3-FCGBP heteromeric complexes in vitro by hydrogen sulfide reduction. This mechanism is consistent with the high $\mathrm{H}_{2} \mathrm{~S}$ concentration in disease tissue. Therefore, this function can be used as a reservoir for biologically active peptides. Currently, it is unclear which signaling pathways and molecular functions are activated after TFF3 binds to FCGBP. TFF3-FCGBP complexes may play a role in innate immune defense of mucous epithelial cells such as oral cavity $[97,98]$.

DMBT-1 is a gene encoding an alternatively spliced protein involved in epithelial regeneration and innate host defense and is significantly upregulated in inflammatory bowel disease [60]. It is a pattern recognition receptor with multiple binding sites to which TFF3 can bind in a calcium-dependent manner. Till date, the role of the TFF3-DMBT1 heterodimer has not been clarified. Considering that animal models lacking DMBT1 and TFF proteins confer increased susceptibility to inflammatory bowel disease, scholars speculate that the DMBT1-TFF3 interaction may play a 


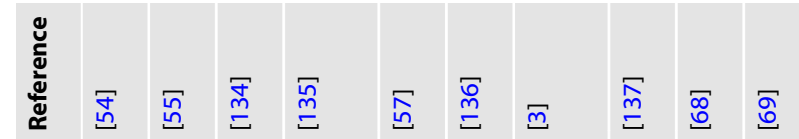

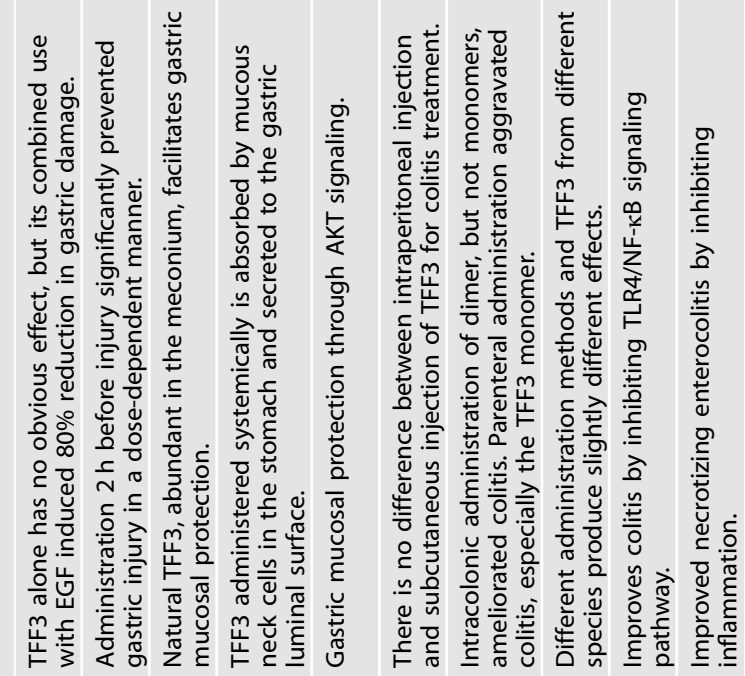

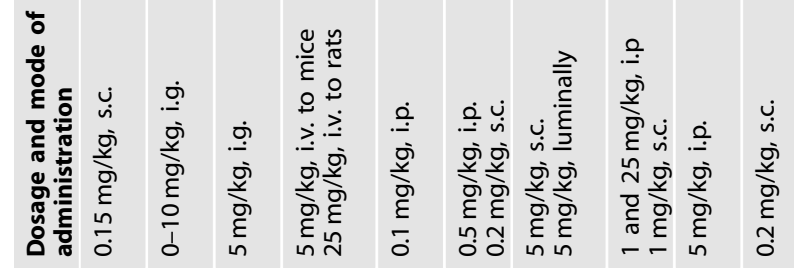

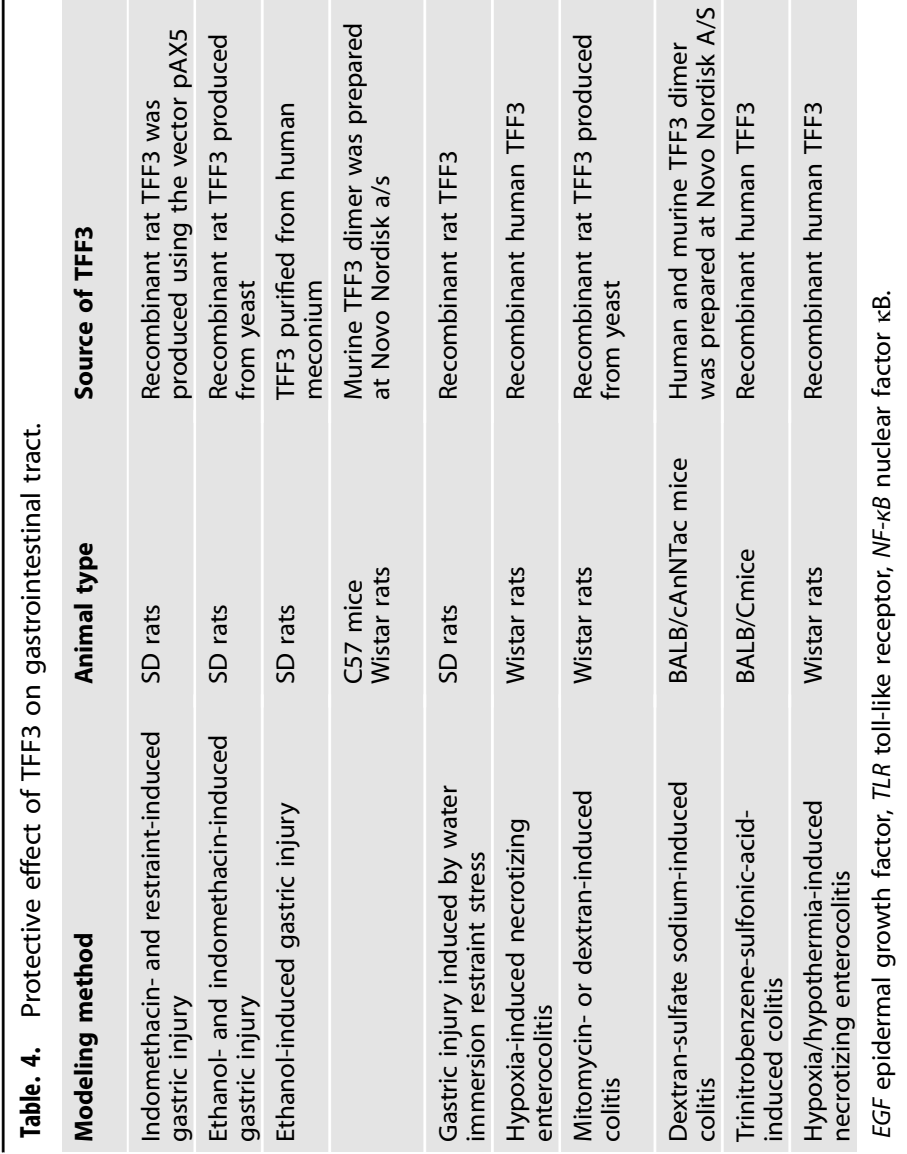




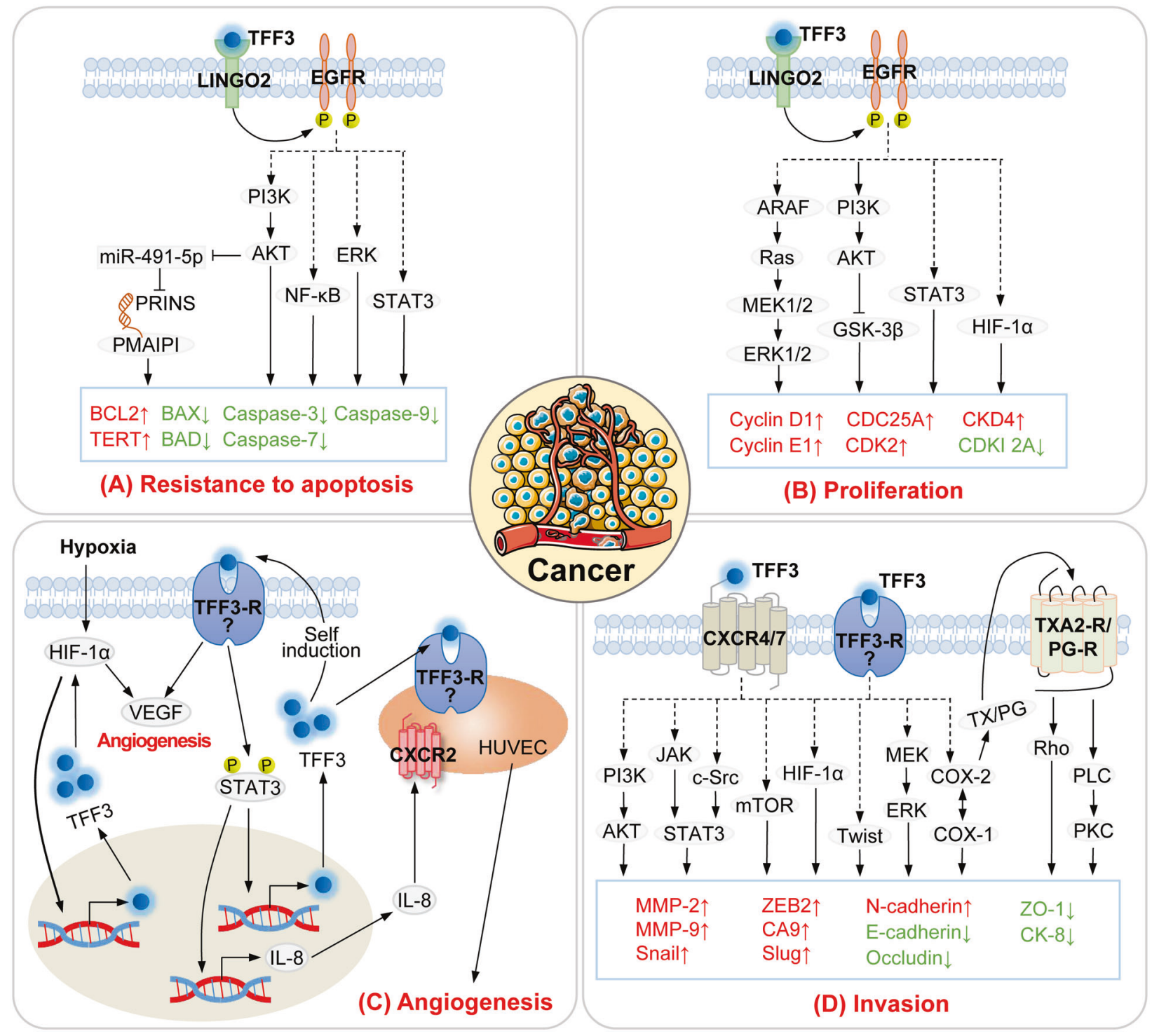

Fig. 2 Carcinogenic mechanism of TFF3. TFF3 affects apoptosis (A) and cell cycle progression (B) by activating MAPK, NF-KB, PI3K, STAT3, and HIF-1 $\alpha$ signaling pathways. TFF3 does not bind to EGFR, but it can induce its phosphorylation. Treatment with the specific EGFR inhibitors tyrphostin A25 and AG1478 can significantly inhibit TFF3-induced cell survival and proliferation. C The promoter region of TFF3 contains the binding sites of HIF-1 $\alpha$ and STAT3, which enables TFF3 to achieve self-induction. On the one hand, TFF3 enhanced the induction of VEGF by HIF-1 $\alpha$; on the other hand, it induced IL-8 expression via STAT3 to promote angiogenesis. D TFF3 regulates the expression of proteins related to cell migration by activating the MAPK, NF- $\mathrm{KB}, \mathrm{PI3K}$, STAT3, mTOR, and HIF-1 $\alpha$ signaling pathways. CXCR, TX2A-R, and PG-R are involved in this biological effect of TFF3. Although TFF3 does not directly bind to TXA2-R and PG-R, it may activate them by increasing the expression of COX or COX derivatives such as prostaglandin E(2) and prostaglandin I(2). The combination of TFF3 and CXCR4/7 can induce cell migration; however, the signaling pathway underlying this effect remains to be verified. Established functions are denoted by solid arrows, whereas unidentified pathways are indicated by question marks. PRINS: psoriasis susceptibility-related RNA gene induced by stress; PMAIP1: phorbol12-myristate-13-acetate-induced protein 1; TERT, telomerase reverse transcriptase; LINGO2, leucine-rich repeat receptor and nogo interacting protein 2; PI3K, phosphoinositide 3-kinase; NF- $\mathrm{BB}$, nuclear factor $\kappa \mathrm{B}$; EGFR, epidermal growth factor receptor; ERK, extracellular signalregulated kinase; STAT:, signal transducer and activator of transcription; GSK-3 $\beta$, glycogen synthase kinase 3 beta; HIF, hypoxia-inducible factor; CDC, cell division cycle; CKDI, cyclin-dependent kinase inhibitor; VEGF, vascular endothelial growth factor; IL, Interleukins; CXCR, C-X-C chemokine receptor; HUVEC, human umbilical vein endothelial cells, mTOR, mammalian target of rapamycin; COX, cyclooxygenase; TXA2-R, thromboxane A2 receptor; PG-R: prostaglandin receptor; MMP, matrix metalloproteinase; ZEB2, zinc finger E-box-binding homeobox 2; CA9, carbonic anhydrase IX; ZO-1, zonula occludens-1; CK-8, cytokeratin-8; PLC, phospholipase C; PKC, protein kinase C.

role in normal gastrointestinal homeostasis and inflammatory bowel disease [60].

\section{TXA2-R and PG-R}

Thromboxane A2 receptor (TXA2-R) and PG-R may be indirect acting receptors for the pro-invasive role of TFF3. Cyclooxygenases (COX) produce TXA2 and various PGs, which promote cell invasion through the TXA2-R and PG- $R$, respectively [99, 100]. Studies showed that TFF3 enhanced epithelial cell invasion in a TXA2-R- and COX-dependent manner; this behavior was abrogated by treatment with inhibitors of COX, TXA2-R, Rho, phospholipase $C$, protein kinase $\mathrm{C}, \mathrm{PI} 3 \mathrm{~K}$, and $\mathrm{mTOR}$ alone $[101,102]$. Although TFF3 does not directly bind to PG-R and TXA2-R, it may activate PG-R/TXA2-R by increasing the expression of COX [103] or COX derivatives such as PGE(2) and 
PGI(2) [104]. Furthermore, Rodrigues et al. discussed the possibility that the COX-derived products TXA2 and PGH(2) are downstream effectors of TFF-induced cell invasion [102].

\section{PAR-2 and CXCR4/7}

For a long time, the search for TFF3-binding proteins with typical receptor characteristics did not made great progress. It was not until 2016 that TFF3 was identified as a low affinity ligand for C-X-C chemokine receptor (CXCR) 4, CXCR7, and PAR-2. PAR-2, which belong to the G-protein-coupled receptor family members, exhibit broad physiological functions and activate various cellular transcription factors by mediating the ERK $1 / 2$ signaling pathway. Using western blotting and immunoprecipitation, researchers demonstrated the interaction between TFF3 and PAR-2, which induced the expression of human beta defensins and suppressed the levels of the cytokines IL-6 and IL- 8 in intestinal epithelial cells [74].

CXCR is widely expressed in various cells and tissues and involved in cell migration, immune cell recruitment, hematopoietic function, embryonic development, and tumor metastasis. Several studies have indicated that MAPK is the downstream pathway of CXCR4/7. Co-expression of CXCR4/7 enhanced the ERK $1 / 2$ and p38 MAPK signaling pathways [105]. Interestingly, the addition of a specific CXC receptor antagonist completely inhibited the enhanced migration of conjunctival epithelial cells stimulated by TFF3; however, the MAPK signal was not affected by the inhibition of CXCR4/7 [106]. This indicated that TFF3 induced intracellular MAPK through other binding targets, such as EGFR, as discussed below.

\section{EGFR and LINGO2}

EGFR is a membrane surface receptor closely related to the growth, proliferation, differentiation, apoptosis, metastasis, and other processes of tumor cells. Till date, no studies have shown that TFF3 directly binds to EGFR. They may interact indirectly. Nevertheless, TFF3 has the ability to cause rapid tyrosine phosphorylation of EGFR [107] and subsequent activation of downstream MAPK pathways [80, 108]. In turn, the specific inhibition of EGFR blocked the differentiation and proliferation of cells promoted by TFF3 $[109,110]$.

LINGO2 belongs to the family of leucine-rich repeat and IgGlike domain proteins with a large extracellular portion (ectodomain), a transmembrane domain, and a short cytoplasmic tail. LINGO2-related genetic variants are associated with obesity, waist circumference, and BMI in different populations [111-113]; they might act as susceptibility genes for gestational diabetes mellitus [114]. Recent studies identified LINGO2 as a key component of TFF3 cellular reactivity, and their binding was observed within $40 \mathrm{~nm}$ of the cell membrane of intestinal epithelial cells. The TFF3-LINGO2 interaction resulted in enhanced EGFR signaling, which could promote wound healing and immunity [75]. However, this may lead to carcinogenic behavior; tissue microarray analysis revealed that LINGO2 expression was significantly increased in advanced gastric cancer, and the overall survival rate of patients with high LINGO2 was significantly lower than that of patients with low LINGO2 [115]. Corresponding to the carcinogenic characteristics of TFF3, we speculate that the enhanced cell motility, angiogenesis, and tumorigenicity observed in LINGO2-overexpressing cells [115] are likely directly related to TFF3.

\section{CLINICAL APPLICATIONS OF TFF-PEPTIDE-BASED THERAPIES}

Currently, only recombination TFF3 has entered clinical practice; it is used for treating ulcerative colitis and oral mucositis (Table 5) and produced by recombinant expression in yeast. Despite the crucial role of TFF3 for gastrointestinal mucosal protection, as demonstrated at the cellular and animal level, these models do

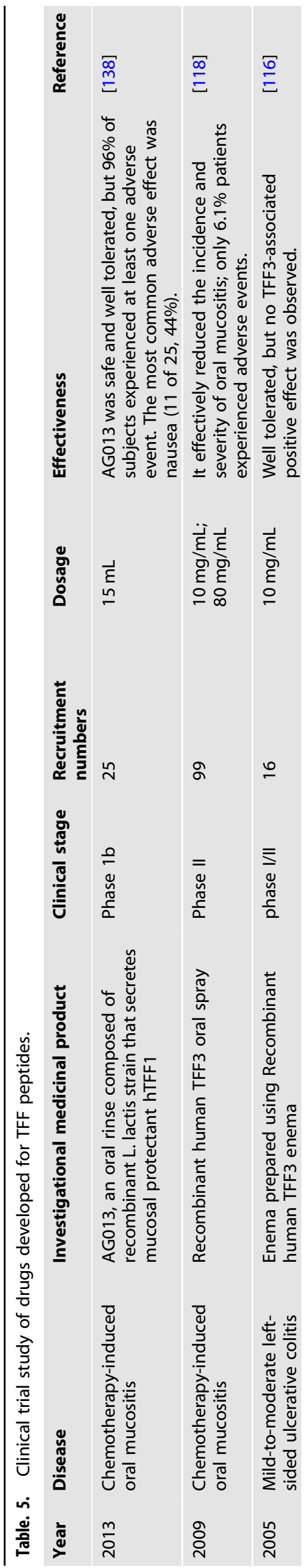


not represent the human situation well. No positive effects of TFF3 were observed in a phase I/II double-blind randomized trial of TFF3 enema combined with oral 5-aminosalicylic acid in the treatment of ulcerative colitis [116]. Compared with increasing the oral dose of mesalazine, TFF3 enema showed no other advantages. The poor effect can be attributed to the insufficient number of cases and route of administration. For example, gavage of colitis mice with TFF1-overexpressing Lactococcus lactis achieved much greater efficacy than oral or rectal administration of pure recombinant TFF1 [117]. Furthermore, intraluminal administration of dimeric TFF3 significantly improved colitis scores in a colitis model. However, systemic administration, especially TFF3 monomer, aggravated colitis severity in rats [3]. These results suggested that different administration pathways have a great impact on TFF peptide function.

Initial success has been achieved with the application of TFF peptides in the form of gargle and aerosol. Peterson et al. observed that prophylactic administration of TFF3 aerosol reduced the incidence and severity of clinically significant oral mucositis in a cohort of colorectal cancer patients [118]. Therefore, TFF3 not only exerts its effect on the digestive system but also served as a promising treatment for mucosal inflammation in various tissues, such as the ocular tissue [119], oral cavity [97, 120], and respiratory tract [121].

\section{CONCLUSIONS AND FUTURE PERSPECTIVES}

TFF3 plays a therapeutic role in a variety of diseases. As a mixed ligand, TFF3 can activate multiple signaling pathways including MAPK, NF-KB, PI3K, STAT3, mTOR, and HIF-1a to repair damaged mucosa, regulate glucose and lipid metabolism; and produce anti-neuroinflammatory, antidepressant, and anti-drug-addictive properties. However, TFF3 is the driving factor of cancer, which is involved in the proliferation, invasion, resistance to apoptosis, and angiogenesis of cancer cells. There needs to be a good balance between its excellent mucosal restitution ability and its carcinogenic function. More in-depth studies are urgently needed to determine the balance point for elucidating the factors that determine the carcinogenic function of TFF3. Moreover, there remain major gaps in the knowledge of TFF3specific receptors, molecular mechanisms, drug-delivery strategies, and physiological significance. These problems are an important reason that prevented TFF3 from being used as a therapeutic target in clinic.

Considering the diverse biological functions of TFF3, mucosal protection would not be the only application of value. For example, TFF3 dimer in the tear film and ocular surface is very promising as a therapeutic agent for dry eye syndrome [119, 122]. TFF3 is expected to be a potential therapeutic target for glucoseand lipid-metabolism diseases since it can affect hepatic fatty acid accumulation [19], stimulate pancreatic $\beta$-cell proliferation [110], and improve insulin sensitivity [28]. TFF3-FCGBP may be a component of new antimicrobial agents, such as for use as artificial saliva. TFF3 exhibits significant neurologic protection after injection of recombinant TFF3 intraperitoneally or in the basolateral amygdala. The combined use of a TFF3 inhibitor with chemotherapeutic drugs exhibited synergistic tumor-suppressive effects, and it may serve as a potential therapy for slowing cancer progression in the future. Further exploration is needed to determine whether TFF3 can interact with LINGO2 of immune cells to participate in intestinal immune response. As the understanding of TFF3 biological function accelerates, its use in clinical medicine can be expected to increase, such as for dry eye disease, neurodegeneration, glycolipid-metabolism disorders, cancer, and immune imbalance. Its potential value for clinical diagnosis will be further explored and demonstrated.

\section{DATA AVAILABILITY}

Data sharing is not applicable to this article as no datasets were generated or analyzed during the current study.

\section{REFERENCES}

1. Muskett F, May F, Westley B, Feeney J. Solution structure of the disulfide-linked dimer of human intestinal trefoil factor (TFF3): the intermolecular orientation and interactions are markedly different from those of other dimeric trefoil proteins. Biochemistry. 2003;42:15139-47.

2. Prest S, May F, Westley B. The estrogen-regulated protein, TFF1, stimulates migration of human breast cancer cells. FASEB J. 2002;16:592-4.

3. Poulsen S, Kissow H, Hare K, Hartmann B, Thim L. Luminal and parenteral TFF2 and TFF3 dimer and monomer in two models of experimental colitis in the rat. Regulatory Pept. 2005;126:163-71.

4. Kinoshita K, Taupin D, Itoh H, Podolsky D. Distinct pathways of cell migration and antiapoptotic response to epithelial injury: structure-function analysis of human intestinal trefoil factor. Mol Cell Biol. 2000;20:4680-90.

5. Bernstein H, Dobrowolny H, Trübner K, Steiner J, Bogerts B, Hoffmann W. Differential regional and cellular distribution of TFF3 peptide in the human brain. Amino Acids. 2015;47:1053-63.

6. Srivatsa G, Giraud A, Ulaganathan M, Yeomans N, Dow C, Nicoll A. Biliary epithelial trefoil peptide expression is increased in biliary diseases. Histopathology. 2002;40:261-8.

7. Rinnert M, Hinz M, Buhtz $P$, Reiher F, Lessel W, Hoffmann W. Synthesis and localization of trefoil factor family (TFF) peptides in the human urinary tract and TFF2 excretion into the urine. Cell Tissue Res. 2010;339:639-47.

8. Jackerott M, Lee Y, Møllgård K, Kofod H, Jensen J, Rohleder S, et al. Trefoil factors are expressed in human and rat endocrine pancreas: differential regulation by growth hormone. Endocrinology. 2006;147:5752-9.

9. Poulsom R, Hanby A, Lalani E, Hauser F, Hoffmann W, Stamp G. Intestinal trefoil factor (TFF 3) and pS2 (TFF 1), but not spasmolytic polypeptide (TFF 2) mRNAs are co-expressed in normal, hyperplastic, and neoplastic human breast epithelium. J Pathol. 1997;183:30-38.

10. Wiede A, Jagla W, Welte T, Köhnlein T, Busk H, Hoffmann W. Localization of TFF3, a new mucus-associated peptide of the human respiratory tract. Am J Respir. Crit Care Med. 1999;159:1330-5.

11. Langer G, Jagla W, Behrens-Baumann W, Walter S, Hoffmann W. Secretory peptides TFF1 and TFF3 synthesized in human conjunctival goblet cells. Invest. Ophthalmol Vis Sci. 1999;40:2220-4.

12. Cook G, Familari M, Thim L, Giraud A. The trefoil peptides TFF2 and TFF3 are expressed in rat lymphoid tissues and participate in the immune response. FEBS Lett. 1999:456:155-9.

13. Taupin D, Podolsky D. Trefoil factors: initiators of mucosal healing. Nat Rev Mol Cell Biol. 2003:4:721-32.

14. Hoffmann W. Trefoil factor family (TFF) peptides and chemokine receptors: a promising relationship. J Med. Chem. 2009;52:6505-10.

15. Mashimo H, Wu D, Podolsky D, Fishman M. Impaired defense of intestinal mucosa in mice lacking intestinal trefoil factor. Science 1996;274:262-5.

16. Beck P, Wong J, Li Y, Swaminathan S, Xavier R, Devaney K, et al. Chemotherapyand radiotherapy-induced intestinal damage is regulated by intestinal trefoil factor. Gastroenterology. 2004;126:796-808.

17. Paulsen F, Woon C, Varoga D, Jansen A, Garreis F, Jäger K, et al. Intestinal trefoil factor/TFF3 promotes re-epithelialization of corneal wounds. J Biol Chem. 2008;283:13418-27.

18. Shah $A$, Leidinger $P$, Keller A, Wendschlag A, Backes $C$, Baus-Loncar $M$, et al. The intestinal factor Tff3 and a miRNA network regulate murine caloric metabolism. RNA Biol. 2011;8:77-81.

19. Wu X, Zheng $H$, Yang R, Luan X, Zhang L, Jin $Q$, et al. Mouse trefoil factor 3 ameliorated high-fat-diet-induced hepatic steatosis via increasing peroxisome proliferator-activated receptor-a-mediated fatty acid oxidation. Am J Physiol Endocrinol Metab. 2019;317:E436-E445.

20. Kozina $N$, Mihaljević $Z$, Lončar $M$, Mihalj $M$, Mišir $M$, Radmilović $M$, et al. Tff3lmpact of high salt diet on cerebral vascular function and stroke in C57BL/ 6N knockout and WT (C57BL/6N) control mice. Int J Mol Sci. 2019;20:5188.

21. Liu S, Roberts D, Zhang B, Ren Y, Zhang L, Wu Y. Trefoil factor 3 as an endocrine neuroprotective factor from the liver in experimental cerebral ischemia/reperfusion injury. PLoS ONE. 2013;8:e77732.

22. Mohammadi-Shemirani P, Sjaarda J, Gerstein H, Treleaven D, Walsh M, Mann J, et al. A mendelian randomization-based approach to identify early and sensitive diagnostic biomarkers of disease. Clin Chem. 2019;65:427-36.

23. Du T, Luo H, Qin $H$, Wang F, Wang $Q$, Xiang $Y$, et al. Circulating serum trefoil factor 3 (TFF3) is dramatically increased in chronic kidney disease. PloS one. 2013;8:e80271. 
24. Astor B, Köttgen A, Hwang S, Bhavsar N, Fox C, Coresh J. Trefoil factor 3 predicts incident chronic kidney disease: a case-control study nested within the Atherosclerosis Risk in Communities (ARIC) study. Am J Nephrol. 2011;34:291-7.

25. Brott D, Furlong S, Adler S, Hainer J, Arani R, Pinches M, et al. Characterization of renal biomarkers for use in clinical trials: effect of preanalytical processing and qualification using samples from subjects with diabetes. Drug Des, Dev Ther. 2015;9:3191-8.

26. Roa GJB, Tortolero GS, Gonzalez JE. Trefoil factor 3 (TFF3) expression is regulated by insulin and glucose. J Health Sci. 2013; https://doi.org/10.17532/jhsci.2013.26.

27. Tran C, Familari M, Parker L, Whitehead R, Giraud A. Short-chain fatty acids inhibit intestinal trefoil factor gene expression in colon cancer cells. Am J Physiol. 1998;275:G85-94.

28. Xue Y, Shen L, Cui Y, Zhang H, Chen Q, Cui A, et al. Tff3, as a novel peptide, regulates hepatic glucose metabolism. PLoS ONE. 2013;8:e75240.

29. Ge H, Gardner J, Wu X, Rulifson I, Wang J, Xiong Y, et al. Trefoil factor 3 (TFF3) is regulated by food intake, improves glucose tolerance and induces mucinous metaplasia. PLoS ONE. 2015;10:e0126924.

30. Zhou F, Zhou J, Wang W, Zhang X, Ji Y, Zhang P, et al. Unexpected rapid increase in the burden of NAFLD in China from 2008 to 2018: a systematic review and meta-analysis. Hepatol (Baltim, Md). 2019;70:1119-33.

31. Guillén N, Navarro M, Arnal C, Noone E, Arbonés-Mainar J, Acín S, et al. Microarray analysis of hepatic gene expression identifies new genes involved in steatotic liver. Physiol Genomics. 2009;37:187-98.

32. Brown A, Olver W, Donnelly C, May M, Naggert J, Shaffer D, et al. Searching QTL by gene expression: analysis of diabesity. BMC Genet. 2005;6:12.

33. Bujak M, Bujak I, Sobočanec S, Mihalj M, Novak S, Cosić $A$, et al. Trefoil factor 3 deficiency affects liver lipid metabolism. Cell Physiol Biochem. 2018;47:827-41.

34. Šešelja K, Bazina I, Welss J, Schicht M, Paulsen F, Bijelić N, et al. Effect of Tff3 deficiency and ER stress in the liver. Int J Mol Sci. 2019;20:4389.

35. Jagla W, Wiede A, Dietzmann K, Rutkowski K, Hoffmann W. Co-localization of TFF3 peptide and oxytocin in the human hypothalamus. FASEB J. 2000;14:1126-31.

36. Probst J, Zetzsche $T$, Weber $M$, Theilemann $P$, Skutella $T$, Landgraf $R$, et al. Human intestinal trefoil factor is expressed in human hypothalamus and pituitary: evidence for a novel neuropeptide. FASEB J. 1996;10:1518-23.

37. Paterson R, Bartlett J, Blennow K, Fox N, Shaw L, Trojanowski J, et al. Cerebrospinal fluid markers including trefoil factor 3 are associated with neurodegeneration in amyloid-positive individuals. Transl Psychiatry. 2014;4:e419.

38. Zou J, Chen Z, Liang C, Fu Y, Wei X, Lu J, et al. Trefoil factor 3, cholinesterase and homocysteine: potential predictors for Parkinson's disease dementia and vascular Parkinsonism dementia in advanced stage. Aging Dis. 2018;9:51-65.

39. Lubka M, Müller M, Baus-Loncar M, Hinz M, Blaschke K, Hoffmann W, et al. Lack of Tff3 peptide results in hearing impairment and accelerated presbyacusis. Cell Physiol Biochem. 2008;21:437-44.

40. Lubka-Pathak M, Shah A, Gallozzi M, Müller M, Zimmermann U, Löwenheim $H$, et al. Altered expression of securin (Pttg1) and serpina3n in the auditory system of hearing-impaired Tff3-deficient mice. Cell Mol life Sci. 2011;68:2739-49.

41. Shi H, Zhu W, Liu J, Luo Y, Si J, Wang S, et al. PI3K/Akt signaling pathway in the basolateral amygdala mediates the rapid antidepressant-like effects of trefoil factor 3. Neuropsychopharmacology. 2012;37:2671-83.

42. Schwarzberg $H$, Kalbacher $H$, Hoffmann W. Differential behavioral effects of TFF peptides: injections of synthetic TFF3 into the rat amygdala. Pharmacol Biochem Behav. 1999:62:173-8.

43. Shi H, Yin X, Song L, Guo Q, Luo X. Neuropeptide trefoil factor 3 improves learning and retention of novel object recognition memory in mice. Behavioural Brain Res. 2012;227:265-9.

44. Li J, Luo Y, Zhang R, Shi H, Zhu W, Shi J. Neuropeptide trefoil factor 3 reverses depressive-like behaviors by activation of BDNF-ERK-CREB signaling in olfactory bulbectomized rats. Int J Mol Sci. 2015;16:28386-28400.

45. Arnold P, Rickert U, Helmers A, Spreu J, Schneppenheim J, Lucius R. Trefoil factor 3 shows anti-inflammatory effects on activated microglia. Cell tissue Res. 2016;365:3-11.

46. Luo $Y$, Han H, Shao J, Gao Y, Yin X, Zhu W, et al. mTOR signalling in the nucleus accumbens shell is critical for augmented effect of TFF3 on behavioural response to cocaine. Sci Rep. 2016;6:27895.

47. Wu P, Shi H, Luo Y, Zhang R, Li J, Shi J, et al. Neuropeptide trefoil factor 3 attenuates naloxone-precipitated withdrawal in morphine-dependent mice. Psychopharmacology. 2014;231:4659-68.

48. Lanas A, Chan F. Peptic ulcer disease. Lancet (Lond, Engl). 2017;390:613-24.

49. Longman R, Douthwaite J, Sylvester P, Poulsom R, Corfield A, Thomas M, et al. Coordinated localisation of mucins and trefoil peptides in the ulcer associated cell lineage and the gastrointestinal mucosa. Gut. 2000;47:792-800.

50. Kouznetsova I, Kalinski T, Meyer F, Hoffmann W. Self-renewal of the human gastric epithelium: new insights from expression profiling using laser microdissection. Mol Biosyst. 2011;7:1105-12.
51. Kouznetsova I, Peitz U, Vieth M, Meyer F, Vestergaard E, Malfertheiner $P$, et al. A gradient of TFF3 (trefoil factor family 3 ) peptide synthesis within the normal human gastric mucosa. Cell Tissue Res. 2004;316:155-65.

52. Alison M, Chinery R, Poulsom R, Ashwood P, Longcroft J, Wright N. Experimental ulceration leads to sequential expression of spasmolytic polypeptide, intestinal trefoil factor, epidermal growth factor and transforming growth factor alpha mRNAs in rat stomach. J Pathol. 1995;175:405-14.

53. Taupin D, Pedersen J, Familari M, Cook G, Yeomans N, Giraud A. Augmented intestinal trefoil factor (TFF3) and loss of pS2 (TFF1) expression precedes metaplastic differentiation of gastric epithelium. Lab Invest. 2001;81:397-408.

54. Chinery R, Playford R. Combined intestinal trefoil factor and epidermal growth factor is prophylactic against indomethacin-induced gastric damage in the rat. Clin Sci. 1995;88:401-3.

55. Babyatsky $M$, deBeaumont $M$, Thim L, Podolsky D. Oral trefoil peptides protect against ethanol- and indomethacin-induced gastric injury in rats. Gastroenterology. 1996;110:489-97.

56. Dignass A, Lynch-Devaney K, Kindon H, Thim L, Podolsky D. Trefoil peptides promote epithelial migration through a transforming growth factor betaindependent pathway. J Clin Invest. 1994;94:376-83.

57. Huang Y, Wang M, Yang Z, Ren Y, Zhang W, Sun Z, et al. viaPretreatment with intestinal trefoil factor alleviates stress-induced gastric mucosal damage Akt signaling. World J Gastroenterol. 2020;26:7619-32.

58. Yu H, He Y, Zhang X, Peng Z, Yang Y, Zhu R, et al. The rat IgGFcyBP and Muc2 C-terminal domains and TFF3 in two intestinal mucus layers bind together by covalent interaction. PLoS ONE. 2011;6:e20334.

59. Beck P, Ihara E, Hirota S, MacDonald J, Meng D, Nanthakumar N, et al. Exploring the interplay of barrier function and leukocyte recruitment in intestinal inflammation by targeting fucosyltransferase VII and trefoil factor 3. Am J Physiol Gastrointest liver Physiol. 2010;299:G43-53.

60. Madsen J, Sorensen G, Nielsen O, Tornøe I, Thim L, Fenger C, et al. A variant form of the human deleted in malignant brain tumor 1 (DMBT1) gene shows increased expression in inflammatory bowel diseases and interacts with dimeric trefoil factor 3 (TFF3). PLoS ONE. 2013;8:e64441.

61. Meyer zum Büschenfelde D, Tauber R, Huber O. TFF3-peptide increases transepithelial resistance in epithelial cells by modulating claudin-1 and -2 expression. Peptides. 2006;27:3383-90.

62. Buda A, Jepson M, Pignatelli M. Regulatory function of trefoil peptides (TFF) on intestinal cell junctional complexes. Cell Commun Adhes. 2012;19:63-68.

63. Aihara E, Engevik K, Montrose M. Trefoil factor peptides and gastrointestinal function. Annu Rev Physiol. 2017;79:357-80.

64. Lin N, Xu L, Sun M. The protective effect of trefoil factor 3 on the intestinal tight junction barrier is mediated by toll-like receptor 2 via a PI3K/Akt dependent mechanism. Biochem. Biophys. Res Commun. 2013;440:143-9.

65. Dürer U, Hartig R, Bang S, Thim L, Hoffmann W. TFF3 and EGF induce different migration patterns of intestinal epithelial cells in vitro and trigger increased internalization of E-cadherin. Cell Physiol Biochem. 2007;20:329-46.

66. Le J, Zhang D, Zhao Y, Qiu W, Wang P, Sun Y. ITF promotes migration of intestinal epithelial cells through crosstalk between the ERK and JAK/STAT3 pathways. Sci Rep. 2016;6:33014.

67. Podolsky D, Gerken G, Eyking A, Cario E. Colitis-associated variant of TLR2 causes impaired mucosal repair because of TFF3 deficiency. Gastroenterology. 2009;137:209-20.

68. Teng $X, X u L$, Zhou $P$, Sun $H$, Sun M. Effects of trefoil peptide 3 on expression of TNF-alpha, TLR4, and NF-kappaB in trinitrobenzene sulphonic acid induced colitis mice. Inflammation. 2009;32:120-9.

69. Shi L, Zhou P, Xi J, Yu H, Zhang B. Recombinant human trefoil factor 3 ameliorates bowel injury: its anti-inflammatory effect on experimental necrotizing enterocolitis. Int J Pept. 2014;2014:634135.

70. Zhu Y, Tan X. TFF3 modulates NF-\{kappa\}B and a novel negative regulatory molecule of NF-\{kappa\}B in intestinal epithelial cells via a mechanism distinct from TNF-\{alpha\}. Am J Physiol Cell Physiol. 2005;289:C1085-1093.

71. Barrett K. A new twist on trefoils. Focus on "TFF3 modulates NF-\{kappa\}B and a novel regulatory molecule of NF-\{kappa\}B in intestinal epithelial cells via a mechanism distinct from TNF-\{alpha\}". Am J Physiol Cell Physiol. 2005;289: C1069-1071

72. Wang $\mathrm{Y}$, Liang $\mathrm{K}$, Kong $\mathrm{W}$. Intestinal trefoil factor 3 alleviates the intestinal barrier function through reducing the expression of TLR4 in rats with nonalcoholic steatohepatitis. Arch Med Res. 2019;50:2-9.

73. Barrera G, Sanchez G, Gonzalez J. Trefoil factor 3 isolated from human breast milk downregulates cytokines (IL8 and IL6) and promotes human beta defensin (hBD2 and hBD4) expression in intestinal epithelial cells HT-29. Bosn J Basic Med Sci. 2012;12:256-64.

74. Barrera G, Tortolero G. Trefoil factor 3 (TFF3) from human breast milk activates PAR-2 receptors, of the intestinal epithelial cells HT-29, regulating cytokines and defensins. Bratisl Lek Listy. 2016;117:332-9. 
75. Belle N, Ji Y, Herbine K, Wei Y, Park J, Zullo K, et al. TFF3 interacts with LINGO2 to regulate EGFR activation for protection against colitis and gastrointestinal helminths. Nat Commun. 2019;10:4408.

76. Sung H, Ferlay J, Siegel R, Laversanne M, Soerjomataram I, Jemal A, et al. Global cancer statistics 2020: GLOBOCAN estimates of incidence and mortality worldwide for 36 cancers in 185 countries. CA: Cancer J Clin. 2021;71:209-49.

77. Jahan R, Shah A, Kisling S, Macha M, Thayer S, Batra S, et al. Odyssey of trefoil factors in cancer: diagnostic and therapeutic implications. Biochim Biophys Acta Rev Cancer. 2020;1873:188362.

78. Chen R, Chiou Y, Chong Q, Poh H, Tan T, Zhang M, et al. Pharmacological inhibition of TFF3 enhances sensitivity of CMS4 colorectal carcinoma to 5 -fluorouracil through inhibition of p44/42 MAPK. Int J Mol Sci. 2019;20:6215.

79. Lin X, Zhang H, Dai J, Zhang W, Zhang J, Xue G, et al. TFF3 Contributes to epithelial-mesenchymal transition (EMT) in papillary thyroid carcinoma cells via the MAPK/ERK signaling pathway. J Cancer. 2018;9:4430-9.

80. Storesund T, Hayashi K, Kolltveit K, Bryne M, Schenck K. Salivary trefoil factor 3 enhances migration of oral keratinocytes. Eur J oral Sci. 2008;116:135-40.

81. Furuta G, Turner J, Taylor C, Hershberg R, Comerford K, Narravula S, et al. Hypoxia-inducible factor 1-dependent induction of intestinal trefoil factor protects barrier function during hypoxia. J Exp Med. 2001;193:1027-34.

82. Zwaini Z, Alammari D, Byrne S, Stover C. Mode of proximal tubule damage: differential cause for the release of TFF3? Front Immunol. 2016;7:122.

83. Hernández C, Santamatilde E, McCreath K, Cervera A, Díez I, Ortiz-Masiá D, et al. Induction of trefoil factor (TFF)1, TFF2 and TFF3 by hypoxia is mediated by hypoxia inducible factor- 1 : implications for gastric mucosal healing. Br J Pharmacol. 2009;156:262-72.

84. Guleng B, Han J, Yang J, Huang Q, Huang J, Yang X, et al. TFF3 mediated induction of VEGF via hypoxia in human gastric cancer SGC-7901 cells. Mol Biol Rep. 2012;39:4127-34.

85. Sun $Y$, Wang L, Zhou $Y$, Mao X, Deng X. Human trefoil factor 3 induces the transcription of its own promoter through STAT3. Sci Rep. 2016;6:30421.

86. Pandey V, Wu Z, Zhang M, Li R, Zhang J, Zhu T, et al. Trefoil factor 3 promotes metastatic seeding and predicts poor survival outcome of patients with mammary carcinoma. Breast Cancer Res. 2014;16:429.

87. Pandey V, Zhang M, You M, Zhang W, Chen R, Zhang W, et al. Expression of two non-mutated genetic elements is sufficient to stimulate oncogenic transformation of human mammary epithelial cells. Cell Death Dis. 2018;9:1147.

88. Yuan $Z$, Chen D, Chen $X$, Yang $H$, Wei Y. Overexpression of trefoil factor 3 (TFF3) contributes to the malignant progression in cervical cancer cells. Cancer cell Int 2017;17:7.

89. Rivat C, Christine R, Rodrigues S, Sylvie R, Bruyneel E, Erik B, et al. Implication of STAT3 signaling in human colonic cancer cells during intestinal trefoil factor 3 (TFF3) - and vascular endothelial growth factor-mediated cellular invasion and tumor growth. Cancer Res. 2005;65:195-202.

90. Lobie PE, Pandey VK, Subbegowda RK, Basappa B, Dhananjaya MC, Rangappa S. Compounds useful in inhibiting human trefoil factor 3. WO2018226155. Patent. 2018 Dec 13.

91. Poh H, Chiou Y, Chong Q, Chen R, Rangappa K, Ma L, et al. Inhibition of TFF3 enhances sensitivity-and overcomes acquired resistance-to doxorubicin in estrogen receptor-positive mammary carcinoma. Cancers (Basel);11:1528.

92. Zhang M, Wang B, Chong Q, Pandey V, Guo Z, Chen R, et al. A novel smallmolecule inhibitor of trefoil factor 3 (TFF3) potentiates MEK1/2 inhibition in lung adenocarcinoma. Oncogenesis. 2019;8:65.

93. Hoffmann W, Jagla W, Wiede A. Molecular medicine of TFF-peptides: from gut to brain. Histol Histopathol. 2001;16:319-34.

94. Matsuoka Y, Pascall J, Brown K. Quantitative analysis reveals differential expression of mucin (MUC2) and intestinal trefoil factor mRNAs along the longitudinal axis of rat intestine. Biochim Biophys Acta. 1999;1489:336-44.

95. Kobayashi K, Ogata H, Morikawa M, lijima S, Harada N, Yoshida T, et al. Distribution and partial characterisation of IgG Fc binding protein in various mucin producing cells and body fluids. Gut. 2002;51:169-76.

96. Albert T, Laubinger W, Müller S, Hanisch F, Kalinski T, Meyer F, et al. Human intestinal TFF3 forms disulfide-linked heteromers with the mucus-associated FCGBP protein and is released by hydrogen sulfide. J Proteome Res. 2010;9:3108-17.

97. Houben $\mathrm{T}$, Harder $\mathrm{S}$, Schlüter $\mathrm{H}$, Kalbacher $\mathrm{H}$, Hoffmann W. Different forms of TFF3 in the human saliva: heterodimerization with IgG Fc binding protein (FCGBP). Int J Mol Sci. 2019;20:5000.

98. Hoffmann W. Trefoil factor family (TFF) peptides and their diverse molecular functions in mucus barrier protection and more: changing the paradigm. Int J Mol Sci. 2020;21:4535.

99. Fosslien E. Review: molecular pathology of cyclooxygenase-2 in cancer-induced angiogenesis. Ann Clin Lab Sci. 2001;31:325-48.
100. Fukuda R, Kelly B, Semenza G. Vascular endothelial growth factor gene expression in colon cancer cells exposed to prostaglandin E2 is mediated by hypoxia-inducible factor 1. Cancer Res. 2003;63:2330-4.

101. Emami S, Le Floch N, Bruyneel E, Thim L, May F, Westley B, et al. Induction of scattering and cellular invasion by trefoil peptides in src- and RhoA-transformed kidney and colonic epithelial cells. FASEB J. 2001;15:351-61.

102. Rodrigues S, Nguyen Q, Faivre S, Bruyneel E, Thim L, Westley B, et al. Activation of cellular invasion by trefoil peptides and src is mediated by cyclooxygenase- and thromboxane A2 receptor-dependent signaling pathways. FASEB J. 2001;15:1517-28.

103. Loos M, De Creus A, Thim L, Remaut E, Rottiers P. Murine trefoil factor 3 does not directly modulate LPS-mediated dendritic cell function. Scand J Immunol. 2007;66:35-42.

104. Tan X, Chen Y, Liu Q, Gonzalez-Crussi F, Liu X. Prostanoids mediate the protective effect of trefoil factor 3 in oxidant-induced intestinal epithelial cell injury: role of cyclooxygenase-2. J Cell Sci. 2000:;113:2149-55.

105. Décaillot F, Kazmi M, Lin Y, Ray-Saha S, Sakmar T, Sachdev P. CXCR7/CXCR4 heterodimer constitutively recruits beta-arrestin to enhance cell migration. J Biol Chem. 2011;286:32188-97.

106. Dieckow J, Brandt W, Hattermann K, Schob S, Schulze U, Mentlein R, et al. CXCR4 and CXCR7 mediate TFF3-induced cell migration independently from the ERK1/ 2 signaling pathway. Invest Ophthalmol Vis Sci. 2016;57:56-65.

107. Liu D, el-Hariry I, Karayiannakis A, Wilding J, Chinery R, Kmiot W, et al. Phosphorylation of beta-catenin and epidermal growth factor receptor by intestinal trefoil factor. Lab Invest. 1997;77:557-63.

108. Baus-Loncar M, Giraud A. Multiple regulatory pathways for trefoil factor (TFF) genes. Cell Mol life Sci. 2005;62:2921-31.

109. LeSimple P, van Seuningen I, Buisine M, Copin M, Hinz M, Hoffmann W, et al. Trefoil factor family 3 peptide promotes human airway epithelial ciliated cell differentiation. Am J Respir Cell Mol Biol. 2007;36:296-303.

110. Fueger P, Schisler J, Lu D, Babu D, Mirmira R, Newgard C, et al. Trefoil factor 3 stimulates human and rodent pancreatic islet beta-cell replication with retention of function. Mol Endocrinol (Baltim, Md). 2008;22:1251-9.

111. Williams A, Jacobs S, Moreno-Macías H, Huerta-Chagoya A, Churchhouse $C$, Márquez-Luna $C$, et al. Sequence variants in SLC16A11 are a common risk factor for type 2 diabetes in Mexico. Nature. 2014;506:97-101.

112. Locke A, Kahali B, Berndt S, Justice A, Pers T, Day F, et al. Genetic studies of body mass index yield new insights for obesity biology. Nature. 2015:518:197-206.

113. Shungin D, Winkler T, Croteau-Chonka D, Ferreira T, Locke A, Mägi R, et al. New genetic loci link adipose and insulin biology to body fat distribution. Nature. 2015;518:187-96.

114. Su T, Ren $Q$, Lu Y, Tai W, Zhu Y, Li Z, et al. A genetic variant in LINGO2 contributes to the risk of gestational diabetes mellitus in a Chinese population. J Cell Physiol. 2019;234:7012-8.

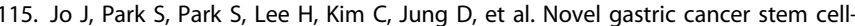
related marker LINGO2 is associated with cancer cell phenotype and patient outcome. Int J Mol Sci. 2019;20:555.

116. Mahmood A, Melley L, Fitzgerald A, Ghosh S, Playford R. Trial of trefoil factor 3 enemas, in combination with oral 5-aminosalicylic acid, for the treatment of mild-to-moderate left-sided ulcerative colitis. Alimentary Pharmacol Ther. 2005;21:1357-64.

117. Vandenbroucke K, Hans W, Van Huysse J, Neirynck S, Demetter P, Remaut E, et al. Active delivery of trefoil factors by genetically modified Lactococcus lactis prevents and heals acute colitis in mice. Gastroenterology. 2004;127:502-13.

118. Peterson D, Barker N, Akhmadullina L, Rodionova I, Sherman N, Davidenko I, et al. Phase II, randomized, double-blind, placebo-controlled study of recombinant human intestinal trefoil factor oral spray for prevention of oral mucositis in patients with colorectal cancer who are receiving fluorouracil-based chemotherapy. J Clin Oncol. 2009;27:4333-8.

119. Schulze U, Sel S, Paulsen F. Trefoil factor family peptide 3 at the ocular surface. A promising therapeutic candidate for patients with dry eye syndrome? Dev Ophthalmol. 2010;45:1-11.

120. Choudhary A, Smitha C, Suresh D. Trefoils: an unexplored natural protective shield of oral cavity. J Oral Biol Craniofacial Res. 2015;5:226-31.

121. dos Santos Silva E, Ulrich M, Döring G, Botzenhart K, Gött P. Trefoil factor family domain peptides in the human respiratory tract. J Pathol. 2000;190:133-42.

122. Schulze U, Hampel U, Sel S, Contreras-Ruiz L, Schicht M, Dieckow J, et al. Trefoil factor family peptide 3 (TFF3) is upregulated under experimental conditions similar to dry eye disease and supports corneal wound healing effects in vitro. Invest Ophthalmol Vis Sci. 2014;55:3037-42.

123. Madsen J, Nielsen O, Tornøe I, Thim L, Holmskov U. Tissue localization of human trefoil factors 1, 2, and 3. J Histochem Cytochem. 2007;55:505-13.

124. Paulsen F, Varoga D, Paulsen A, Tsokos M. Trefoil factor family (TFF) peptides of normal human Vater's ampulla. Cell Tissue Res. 2005;321:67-74.

125. Jagla W, Wiede A, Hinz M, Dietzmann K, Gülicher D, Gerlach K, et al. Secretion of TFF-peptides by human salivary glands. Cell tissue Res. 1999;298:161-6. 
14

126. Wiede A, Hinz M, Canzler E, Franke K, Quednow C, Hoffmann W. Synthesis and localization of the mucin-associated TFF-peptides in the human uterus. Cell Tissue Res. 2001;303:109-15.

127. Vestergaard E, Nexo E, Wendt A, Guthmann F. Trefoil factors in human milk. Early Hum Dev. 2008;84:631-5.

128. Langer G, Walter S, Behrens-Baumann W, Hoffmann W. [TFF peptides. New mucus-associated secretory products of the conjunctiva]. Der Ophthalmologe: Zeitschrift der Deutschen Ophthalmologischen Gesellschaft. 2001;98:976-9.

129. Paulsen F, Hinz M, Schaudig U, Thale A, Hoffmann W. TFF peptides in the human efferent tear ducts. Invest Ophthalmol Vis Sci. 2002;43:3359-64.

130. Steven P, Schäfer G, Nölle B, Hinz M, Hoffmann W, Paulsen F. Distribution of TFF peptides in corneal disease and pterygium. Peptides. 2004;25:819-25.

131. Taupin D, Kinoshita K, Podolsky D. Intestinal trefoil factor confers colonic epithelial resistance to apoptosis. Proc Natl Acad Sci USA. 2000;97:799-804.

132. Fu T, Znalesniak E, Kalinski T, Möhle L, Biswas A, Salm F, et al. TFF peptides play a role in the immune response following oral infection of mice with toxoplasma gondii. Eur J Microbiol Immunol. 2015;5:221-31.

133. Taupin D, Wu D, Jeon W, Devaney K, Wang T, Podolsky D. The trefoil gene family are coordinately expressed immediate-early genes: EGF receptor- and MAP kinase-dependent interregulation. J Clin Invest. 1999;103:R31-38.

134. Yu K, Jiang S, Lin M, Wu J, Lin J. Extraction and purification of biologically active intestinal trefoil factor from human meconium. Lab Invest. 2004;84:390-2.

135. Kjellev S, Nexø E, Thim L, Poulsen S. Systemically administered trefoil factors are secreted into the gastric lumen and increase the viscosity of gastric contents. $\mathrm{Br}$ J Pharmacol. 2006;149:92-99.

136. Zhang B, Yu H, Sheng $\mathrm{Z}$, Luo $\mathrm{H}$, Yu J. The therapeutic effect of recombinant human trefoil factor 3 on hypoxia-induced necrotizing enterocolitis in immature rat. Regulatory Pept. 2003;116:53-60.

137. Kjellev S, Thim L, Pyke C, Poulsen S. Cellular localization, binding sites, and pharmacologic effects of TFF3 in experimental colitis in mice. Digestive Dis Sci. 2007;52:1050-9.

138. Limaye S, Haddad R, Cilli F, Sonis S, Colevas A, Brennan M, et al. Phase 1b, multicenter, single blinded, placebo-controlled, sequential dose escalation study to assess the safety and tolerability of topically applied AG013 in subjects with locally advanced head and neck cancer receiving induction chemotherapy. Cancer. 2013;119:4268-76.

\section{ACKNOWLEDGEMENTS}

The authors would like to thank the Key Project of National Natural Science Foundation of China (\#81830113), the National Key R \& D Plan "Research on Modernization of Traditional Chinese Medicine" (\#2018YFC1704200), the Major Basic and Applied Basic Research Projects of Guangdong Province of China (\#2019B030302005), and the Medical Science and Technology Foundation of Guangdong Province (\#B2020023) for supporting this work. Figure 1 and Figure 2 were modified from Servier Medical Art (http://smart.servier.com/), licensed under a Creative Common Attribution 3.0 Generic License. (https://creativecommons.org/licenses/by/3.0/).

\section{AUTHOR CONTRIBUTIONS}

YY contribute to concept, direction, framework design, writing, and article revision; ZL substantial contribution to article writing, drawing, tabulation and collect the related papers; QL contribute to reference checking, data acquisition and the writing of some chapters; WB contribute to critical revision of important intellectual content; and JG contributed to concept, direction, ctitical revision and final approval of the version to be published.

\section{FUNDING INFORMATION}

This work was supported by the Key Project of National Natural Science Foundation of China (\#81830113); the National Key R \& D Plan "Research on Modernization of Traditional Chinese Medicine" (\#2018YFC1704200); the Major Basic and Applied Basic Research Projects of Guangdong Province of China (\#2019B030302005); and the Medical Science and Technology Foundation of Guangdong Province (\#B2020023).

\section{COMPETING INTERESTS}

The authors declare no competing interests.

\section{ETHICS}

This work does not include animal experiments and clinical trials involving patients.

\section{ADDITIONAL INFORMATION}

Supplementary information The online version contains supplementary material available at https://doi.org/10.1038/s41419-022-04504-6.

Correspondence and requests for materials should be addressed to Jiao Guo.

Reprints and permission information is available at http://www.nature.com/ reprints

Publisher's note Springer Nature remains neutral with regard to jurisdictional claims in published maps and institutional affiliations.

\section{c) (i)}

Open Access This article is licensed under a Creative Commons Attribution 4.0 International License, which permits use, sharing, adaptation, distribution and reproduction in any medium or format, as long as you give appropriate credit to the original author(s) and the source, provide a link to the Creative Commons license, and indicate if changes were made. The images or other third party material in this article are included in the article's Creative Commons license, unless indicated otherwise in a credit line to the material. If material is not included in the article's Creative Commons license and your intended use is not permitted by statutory regulation or exceeds the permitted use, you will need to obtain permission directly from the copyright holder. To view a copy of this license, visit http://creativecommons. org/licenses/by/4.0/.

(c) The Author(s) 2022 